\title{
doispontos:
}

\section{Bernard Stiegler, pensador da tecnologia e do humano}

\author{
Moysés Pinto Neto \\ moysespintoneto@gmail.com \\ Universidade Luterana do Brasil, Canoas, Brasil
}

\begin{abstract}
Resumo: Este artigo é uma introdução geral ao pensamento de Bernard Stiegler em torno da relação entre técnica e humano. Stiegler desconstroi a tradição filosófica que costumava separar technê e episteme com um enfoque histórico e materialista, a fim de provar como é impossível pensar a humanidade sem a técnica. Portanto, a relação não é de oposição, como a tradicional metafísica do espírito defende, mas composição, do modo como defendem Gilbert Simondon, Jacques Derrida, Andre Leroi-Gourhan e Gilles Deleuze.
\end{abstract}

Palavras-chave: Humano; técnica; Stiegler; programa; antropologia; desconstrução.

\begin{abstract}
This paper is a general introduction to Bernard Stiegler's thinking about the relation between technique and human. Stiegler deconstructs the philosophical tradition that used to separate teckhnê and episteme with a historical and materialist approach in order to prove how it is impossible to think humanity without technique. Therefore, the relation is not one of opposition, like the traditional metaphysics of spirit defends, but one of composition, as thinkers like Gilbert Simondon, Jacques Derrida, Andre Leroi-Gourhan and Gilles Deleuze defend. Keywords: Human; technique; Stiegler; program; anthropology; deconstruction.
\end{abstract}

\section{INTRODUÇÃO}

Bernard Stiegler, pensador francês em plena atividade, pertence a um grupo de filósofos contemporâneos que, além de herdeiros de uma longa tradição filosófica, procura o cruzamento de diversas áreas fazendo do diálogo com as ciências contemporâneas algo extremamente produtivo. Nesse sentido, procura mesclar contribuições da tecnologia, psicanálise, economia política, sociologia, paleontologia, biologia, medicina e outras áreas para construir um sistema filosófico erguido sobre um tripé: filosofia da tecnologia, antropologia filosófica e filosofia social. A partir de Gilbert Simondon e Bertrand Gille, Stiegler busca reconstruir uma ontologia dos sistemas técnicos. Com Andre Leroi-Gourhan, Martin Heidegger e Edmund Husserl trabalha uma antropologia filosófica de viés materialista, fazendo confluir a questão do humano e da técnica. Por fim, com Karl Marx, Max Weber, Sigmund Freud e Jean-François Lyotard produz uma nova crítica da economia política sustentada sobre a questão da economia libidinal. Ainda como as mais decisivas influências, presentes em todos os momentos dos seus escritos como espécie de cimentação última, estão Gilles Deleuze, Simondon e, mais do que todos os mencionados, Jacques Derrida (STIEGLER, 2009). Poder-se-ia afirmar, inclusive, que o sistema de Stiegler é uma espécie de desenvolvimento positivo da filosofia de Derrida (dentre os múltiplos possíveis), repavimentando o terreno após a desconstrução da metafísica clássica e de seu jogo oposicional que o filósofo franco-argelino realizou.

O presente texto tem a finalidade de introduzir ao leitor brasileiro o pensamento do filósofo francês, ainda pouco conhecido entre nós ${ }^{1}$. Procurar-se-á elaborar o itinerário a partir dos três pontos fundamentais do sistema de Stiegler: ontologia dos sistemas técnicos, antropologia filosófica e articulação do humano e da técnica a partir da industrialização da memória. A filosofia social, pautada sobre a crítica da economia política consumerista e mais presente nos trabalhos recentíssimos do autor, exigiria outro trabalho específico. 


\section{ONTOLOGIA DOS SISTEMAS TÉCNICOS: A MATÉRIA INORGÂNICA ORGANIZADA}

Pode-se dizer que o ponto de desavença de Stiegler com a filosofia da tecnologia tradicional consiste na separação grega entre seres vivos e não-vivos, origem da divisão entre tecknê e episteme (STIEGLER, 1998, p. 1). Stiegler procura mostrar como no mundo trágico homérico essa divisão não era realizada, uma vez que ela é herdeira da disputa entre filósofos - donos da episteme - e sofistas, donos da tecknê. Essa divisão permanece patente, por exemplo, na Escola de Frankfurt, herdeira da tradição kantiana, pensando a relação entre humano e técnica como relação de meio-fim, separada, portanto, da esfera ética reflexiva própria do humano. Stiegler dirige claramente o alvo para a oposição que Jürgen Habermas efetua entre razão instrumental e razão comunicativa. A técnica é nesse caso um meio que perverte a livre-comunicação humana na sua esfera propriamente dialogal (STIEGLER, 1998, pp. 10-14; 2001, pp. 65-74). Em Stiegler, ao contrário, é necessário repensar a relação humano/técnica a partir da luz da composição, não da oposição. Para tanto, inicia a partir de Gille, Leroi-Gourhan e Simondon a repensar a tecno-logia de forma diferente da tradição antropológica que predomina na filosofia, apresentando, no primeiro volume de La technique et le temps - la faute de Epimethée, um apanhado geral das teses desses autores dissonantes da visão instrumentalista.

Para Gille, é preciso elaborar uma história material dos sistemas técnicos entendendo seus progressos não como resultado da história cultural, mas fundamentalmente ligada aos próprios sistemas técnicos em si mesmos. Um sistema é constituído pela estabilização da evolução técnica com aquisições prévias e tendências estruturais determinadas por um jogo de interdependências e invenções complementando um ao outro. O sistema técnico é, assim, uma unidade temporal a partir da qual se tem um ponto de equilíbrio concretizado em uma tecnologia particular. A invenção, nesse sentido, não é resultado de uma calculabilidade científica que incide sobre o objeto; é a própria "empiricidade" do objeto que determina a inovação que era imponderável antes do processo temporal que se desenrolou a partir do seu desenvolvimento. Não há, por isso, como pré-determinar a evolução de um sistema técnico, cujas possibilidades só se abrem e são determinadas a partir de um estado novo adquirido numa linhagem tecnológica. A linhagem tecnológica tende, assim, para uma progressiva solidariedade e complexidade dos elementos interdependentes. A partir desse re-equacionamento, a relação entre o sistema social e o sistema técnico torna-se mais complexa do que supõe a lógica instrumental tradicional. Há uma necessidade de ajuste permanente entre um e outro e momentos-limite em que a inovação técnica pode desestabilizar todos os demais sistemas, criando resistências (STIEGLER, 1998, pp. 25-7 e 29-43).

Stiegler segue aprofundando a questão a partir de Leroi-Gourhan, paleontólogo postulador de uma universalidade técnica. Para o último, há tendências técnicas universais independentes dos grupos locais humanos, pois a tendência atravessa as culturas (chamadas de "sistemas étnicos"). A dinâmica tecnológica, assim, é imanente, entrando em complexa relação com sistemas étnicos particulares. Segundo Leroi-Gourhan, há um acoplamento do humano com a matéria a partir da técnica, sendo esse o fator preponderante a ser analisado na hominização. $\mathrm{O}$ ambiente tem tendências que implicam a inscrição e moldagem do vivo na matéria inerte, em uma espécie de "determinismo zootecnológico". Os objetos técnicos são, assim, espécies de órgãos dos seres vivos. $\mathrm{O}$ "gênio" das culturas é substituído por tendências técnicas que se irradiam em círculos concêntricos a partir de um jogo composicional com os sistemas étnicos. A matéria não-viva, assim, seria guiada por tendências de organização irredutíveis aos níveis antropológicos, mas selecionando formas de organização com o humano, organizando-o e se autoorganizando (STIEGLER, 1998, pp. 43-61).

O específico do humano, no caso, é a possibilidade de um sistema protético que continua a vida por outros meios que não ela própria, isto é, pela matéria inorgânica. As negociações entre ambientes tentarão equacionar as tendências. A tendência, por outro lado, somente aparece a partir das relações internas, pois não há possibilidade de classificação a priori, uma vez que isso somente aparece no desenrolar do tempo. Leroi-Gourhan chama de "ambiente interior" o aspecto étnico, isto é, a cultura, envolvendo com isso tradições, a memória coletiva (é externa ao indivíduo, não-genética, mas quase-biológica) e de "ambiente exterior", natural, inerte, mas também carregando objetos e ideias de grupos humanos diferentes. $\mathrm{O}$ grupo étnico é a materialização de uma tendência que atravessa o ambiente técnico. Os grupos técnicos, no entanto, tendem a se tornar autônomos, dissolvendo o ambiente interno no externo a partir da industrialização. O ambiente étnico pode resistir à inovação técnica, mas a tendência é que ela se imponha (STIEGLER, 1998, pp. 61-5 e 164-179). 
Gilbert Simondon, por fim, é quem sepulta de vez a hipótese antropológica da evolução técnica. O humano não é mais ator intencional da dinâmica, mas apenas seu operador. Não há uma "alienação da cultura nas máquinas", mas um mal-entendido sobre a essência das máquinas. $\mathrm{O}$ humano não está fora, mas dentro desse agrupamento maquínico, executando uma quase-intencionalidade da qual o objeto técnico é carregador. A mecanologia ou tecnologia seria, assim, a ciência do processo de concretização dos objetos técnicos, cuja dinâmica não é regida por uma intencionalidade humana, mas pelo objeto em si mesmo tendente à indeterminação (e não automação, chamada de "mito do robô") como sua maior virtude. Stiegler nomeia esse processo de organização da matéria inorgânica "maiêutica tecnológica" (STIEGLER, 1998, pp. 175-9; SIMONDON, 1989, pp. 19-49 e 113-58).

\section{ANTROPOLOGIA E SISTEMAS TÉCNICOS}

A partir desses três autores, Stiegler - seguindo os passos de Derrida (DERRIDA, 1967; 2004) - pode refutar a hipótese "cerebralista" de Rousseau, tida como exemplar da ideia de descontinuidade do humano em relação aos processos históricos evolucionários. Para tanto, segue uma metodologia materialista ao pressupor que as ficções transcendentais dadas como a priori atemporais do humano podem ser melhor equacionadas a partir das ciências da origem (pré-história, paleontologia e arqueologia). Com isso, Stiegler irá deflacionar ao extremo a ideia de natureza humana.

A antropologia tradicional tende a opor humano e técnica. Além disso, é devedora da ideia de origem como queda. Há uma "queda da alma" no corpo, no sensível, uma pureza que é contaminada pela sociedade e pela técnica. Rousseau é o pai da questão central da antropologia clássica: "o que é o humano?”. Para Rousseau, trata-se de uma natureza pura que se corrompeu, provocando um distanciamento da origem a partir da técnica. Segundo ele, antes de tudo vem a igualdade, inclusive como condição que antecede a própria história. Esse homem mítico não manipula, tem tudo à mão, apenas imita os animais. Até descobrir a técnica, origem da desigualdade e da civilização. O homem original é completo; a exteriorização é a própria queda, pois originalmente tudo estava dentro. Essa desnaturalização acontece, sobretudo, em face da morte. $\mathrm{O}$ selvagem não tem relação com a morte nem com o tempo: para ele tudo é eterno presente, estático, imutável. É a vertigem da morte que provoca o aparecimento da técnica e com isso a "segunda origem" (STIEGLER, 1998, pp. 82-118).

O que a paleontologia irá demonstrar, contudo, contra Rousseau e seus continuadores (conscientes ou inconscientes), é que nunca houve essa "origem". Em outros termos, esse humano em pleno equilíbrio que é sucedido pela queda jamais existiu. Humano e proteticidade sempre andaram juntos, pois o humano está ligado a uma suplementação em que tudo é mediado, tecnificado. Há, portanto, uma falta na origem, isto é, uma ausência de origem, no sentido de que o que acompanha o homem desde o início é exatamente aquilo que não é humano, isto é, a técnica. Stiegler irá chamar isso da falta de Epimeteu, a ausência de origem à medida que o processo de formação do humano está em permanente referência a uma exterioridade técnica. O mais próprio é o impróprio, a origem é a falta dela. Lembrando Derrida, Stiegler utiliza a ideia de diferença (différance) como um efeito de retorno, um après-coup que constitui a origem a posteriori, como um suplemento que se superpõe retrospectivamente (STIEGLER, 1998, pp. 135-60).

O processo de hominização, para Stiegler, está ligado à epiflogênese. A corticalização na passagem ao Neandertal é também efetuada na pedra, na lenta evolução da técnica de cortar pedras - evolução lenta como uma espécie de deriva genérica na qual o humano é menos o operador que o resultado. Esse processo envolve o prosseguimento da evolução da vida por outros meios não-vivos, programação que atravessa a distinção homem/animal e homem/máquina enquanto liberação de memória. O aparecimento do humano é também o aparecimento da técnica, mas o curioso para nossos vícios mentais é que é também o aparecimento de uma exterioridade sem uma interioridade que a preceda. A ferramenta inventou o homem, e não o inverso. Exterior e interior são constituídos por um movimento que inventa ambos, como se houvesse uma maiêutica tecnológica chamada humanidade (STIEGLER, 1998, pp. 175-9; ver ainda LEROI-GOURHAN, 1983a, p. 31; 1983b, p. 51).

Assim, Stiegler contrapõe ao mito da segunda origem o processo descrito por Leroi-Gourhan: ao começar pelos pés, rechaça-se a ideia de um milagre espiritual ocorrente em um animal (LEROI-GOURHAN, 1983a, p. 150). O psíquico tem sua origem numa organização específica, na sua mecânica e sistema motor que proporcionaram, pela dinâmica do esqueleto, a liberação da mão e daí a utilização de ferramentas, 
órgãos móveis que irão pedir o movimento da face mais tarde. Se a mão libera a fala, a linguagem está diretamente conectada com essa proteticidade. O humano é como um esqueleto exumado. Mobilidade, e não inteligência, é o fundamental do processo de liberação, sendo a inteligência apenas uma espécie de mobilidade. A consciência, assim, é técnica, liberação da pura deriva genética (STIEGLER, 1998, pp. 183-203). O interior e o exterior se formam no mesmo golpe, em uma composição. Stiegler rejeita qualquer tentativa de diferenciação entre espírito e técnica - inclusive a traçada por Leroi-Gourhan para propor uma maiêutica instrumental como uma "protoestágio" do espelho no qual córtex e ferramenta são co-determinados, efeito reflexo em que ambos são formados e deformados. Assim, a intelectualidade reflexiva é desde sempre tendência da tecnicidade, sem que seja possível traçar qualquer linha que separe o simbólico - espiritual, cultural, etc. - do técnico. O trabalho do humano não é um processo interno, mas trabalho do fora como processo de diferenciação e antecipação - enquanto inscrição em memória suplementar que livra da inscrição genética, subindo até o nível industrial e das biotecnologias. Nesse processo, o que está em jogo é, sobretudo, o tempo que é ganho a partir da organização inorgânica da memória.

Após desenvolver a crítica de Leroi-Gourhan ao cerebralismo de Rousseau e criticar o próprio paleontólogo por ter repetido no limite o mito da segunda natureza, Stiegler passa a uma fenomenologia da tecnicidade humana. Recupera, com isso, a mitologia grega para lembrar que a Grécia arcaica pensava o trágico enquanto tecnicidade a partir do mito de Prometeu e Epimeteu. Antes da metafísica - que separa a tecknê, domínio do artificial e da hybris, do logos, domínio da aletheia e do metron - a Grécia trágica pensava essa topologia de outro modo: de um lado, os imortais, de outro, os sem-conhecimento da morte (animais), entre eles, a vida técnica, os que morrem. O mito de Prometeu só se explica a partir do esquecimento de Epimeteu, que esquece de doar a qualidade humana, fazendo seu irmão trazer a tecnicidade. Assim, primeiro há o esquecimento, ou seja, a falta, para após - em um atraso originário (sobre)vir a reflexividade e lembrança (STIEGLER, 1998, pp. 183-203).

Stiegler aproxima-se de Heidegger para pensar a questão da tradição como herança constituída epifilogeneticamente, isto é, a partir de um suporte protético, e não ctônico. A origem é epimetéica, ou seja, faltosa e ao mesmo tempo já-dada, no sentido de contingente, construída tecnicamente. Heidegger interpreta esse tempo intramundano como inautêntico, propondo a autenticidade desde o ser-para-amorte que se apropria do tempo, mas não há tempo sem calendaridade, relógio, técnica. O intervalo que separa o esquecimento inaugural de Epimeteu - a falta de origem - é o que permite pensar o tempo como tempo diferido, fazendo a experiência de um já-dado que abre o futuro como indeterminado. Heidegger quer entender essa tecnicidade como queda, mas ignora que é a própria tecnicidade que abre a possibilidade da diferença. Assim, a analítica existencial precisa ser completada pela epifilogênese (STIEGLER, 1998, pp. 239-76).

\section{A DESORIENTAÇÃO}

Após expor o caráter técnico do Dasein, Stiegler procura pensar como ele se situa no atual modelo da industrialização da memória. Ingressamos no segundo volume de La technique et le Temps, nomeado $\mathrm{La}$ désorientation, onde procura pensar a questão da técnica na contemporaneidade. No mundo clássico, a estabilidade era pensada como regra, sendo a mudança ilusão ou monstruosidade. A partir da tecnociência e sua respectiva velocidade de tempo real, vivemos uma desorientação: perda da cardinalidade (Oriente x Ocidente) e calendaridade. Stiegler, no entanto, quer mostrar que essa desorientação é originária, evitando com isso cair em opções reacionárias e nostálgicas. A história do homem, como vimos, é história das tendências técnicas e a relação entre ambos não é de oposição, mas transductiva (STIEGLER, 1996, pp. 16-20).

Bernard Stiegler começa nomeando o que chama de "Época Ortográfica". Nesse ponto, faz uma inversão do foco da Gramatologia: enquanto esta demonstra o fonocentrismo da metafísica clássica e seu esgotamento, Stiegler foca exatamente em como o ortograma atuou até esse momento, constituindo a possibilidade da sua superação na atualidade. Para evitar esse "fonocentrismo" (em uma estratégia ligeiramente ambígua em relação à Gramatologia), Stiegler começa pela fotografia, utilizando o famoso $A$ Câmara Clara de Roland Barthes. A fotografia é uma conjugação de realidade, em que o passado se mostra exatamente como foi. Há uma certeza que supera a pintura, pois há certeza de que o referente efetivamente existiu. Essa conjunção, contudo, ainda é um passado diferido, que vem como fantasma, passado que se presentifica com atraso. A fotografia demonstra, com isso, que a tekhnê dá o tempo ao mesmo tempo 
que casa a incerteza no coração da certeza a partir do punctum. A ortothesis, assim, embora padrão de orientação baseado na memória direita, reta, carrega consigo um ponto de indeterminação na sua própria constituição como tal. O que faz a certeza faz também a incerteza (STIEGLER, 1996, pp. 23-54).

O mesmo acontece com a escritura linear, que é condição da fotografia. Retomando o diálogo Husserl/ Derrida na Origem da Geometria, Stiegler procura demonstrar como a escritura linear é condição de possibilidade da idealidade. A inteligibilidade apela a uma exatidão do registro de significação. Pensar literalmente é aceder ao jogo diferencial da escrituralidade originária da língua pela possibilidade de poder voltar a ela identicamente. A escritura, assim, é condição da geometria, à medida que a possibilidade de registro é que abriu o suporte para a demonstração. Fotografia e cinema não teriam sido possíveis sem esse suporte capaz de encurtar o tempo com a certeza apriorística da exatitude. Não há idealidade sem retencionalidade instrumental, isto é, sem técnica: eidos e logos são desde sempre tecnológicos. Com ela, foram inventados novos objetos, dos matemáticos aos políticos. Somente obliterando a ortothesis a metafísica pôde constituir o privilégio da phoné (STIEGLER, 1996, pp. 57-60; 2001, pp. 69-123).

Retomando as raízes história da escrita ortográfica, Stiegler faz então uma crítica a Bottero, exatamente idêntica à que faz a Leroi-Gourhan em relação à passagem do Zinjantropo ao Neandertal, quanto à passagem da escritura cuneiforme para a literal. Segundo o filósofo, não há uma racionalidade que precede a constituição da escritura literal de modo a formar o ortograma; este já está inserido como tendência na escritura cuneiforme. A passagem da escritura cuneiforme para a literal implica um processo de conservação de memória em suporte exterior, de um lado, e separação do contexto, de outro, quer dizer, a capacidade de separar a linguagem do contexto vivido, podendo acessar o não-vivido. Contudo, ao mesmo tempo que a ortothesis proporciona a exatidão, também, ao separar-se do vivido, aumenta a inexatidão, movimento de tempo diferido inerente à textualidade que Jacques Derrida seguidamente explorou. O pensamento faz a repetição, e o pensamento crítico, a repetição acumulativa e formal, isto é, a releitura dessa textualidade (STIEGLER, 1996, pp. 60-74).

Sabemos desde a Grécia que a escritura ortográfica suspendia a autoridade dos programas tradicionais. Não se trata de avanço da tecnologia sobre a cultura, pois a cultura se constituiu tecnologicamente enquanto reconstrução do aí por meio da memorização, isto é, diferindo. Mas pode haver mudança de programação, e a escritura é o hypokeimemon proton inclinado à ortoteticidade. A escritura linear e fonológica é uma epokhê programática que suspende as tradições, isto é, os programas. Hoje, com as tecnologias numéricas, esse processo de desterritorialização atingiu níveis inéditos, provocando a desrealização do tempo e do espaço, ou a destruição do contexto (STIEGLER, 1996, pp. 74-5).

\section{INDÚSTRIAS DE PROGRAMAS E TEMPO REAL}

O tempo real típico das indústrias de programação de hoje em dia, sobretudo dos mass media, incrementa a velocidade provocando um curto-circuito no processo. Com ele, a técnica tenta resolver ela própria o problema do atraso por meio da delegação a um automatismo, provocando uma destemporização.

A desorientação nasce pelo fato de que as tradições, o sistema étnico, já eram em si mesmas programações construídas desde uma desorientação originária. As tradições, em outros termos, são programas que agem mediante repetição para a coesão do grupo e unidade étnica. Leroi-Gourhan buscava construir, inclusive, uma programática geral: sendo programa o conceito que atravessa a animalidade, humanidade e tecnicidade. Hoje, com as indústrias de programas de massa, entramos numa espécie de arquiepokhalidade, isto é, suspensão de todos os programas pela perda da comunalidade com a urbanização e industrialização, transferindo as cadeias operatórias a automatismos. O quem está esmagado pelo quê e ossintomas disso estão postos ao longo de toda filosofia do século XX - que é a filosofia da desaparição do mito da interioridade - e da desconstrução objetiva dessa interioridade pelas ciências cognitivas.

Desde o século XVIII, com o aparecimento da imprensa, surgem sistemas gigantescos de memória coletiva. O homem se torna mais fraco que seu "cérebro artificial". O sistema técnico, com isso, absorve o sistema étnico. As próteses levam a um questionamento do quem-indivíduo a partir da captura da última etapa de exteriorização: a imaginação. Com a progressiva industrialização da memória, os programas midiáticos ocupam cada vez mais esse espaço imaginário. A questão, contudo, é agora orientada para fins econômicos a partir do valor da informação - hoje há uma transferência da indústria do "metal pesado" para o imaterial e grande parte da crise em que vivemos está relacionada a isso - crise da "velha indústria". 
O surgimento da informática ocorre nesse ponto enquanto concretização da cibernética - informação mais automatismo. A informação é o critério de valor que se desfaz na exata medida de sua difusão. Por isso, a informação é uma mercadoria política e a informática é uma exploração industrial do valor da informação. Informática e biotecnologia são, hoje em dia, o essencial das indústrias contemporâneas de memória. Ela se potencializa a partir do surgimento da telemática - fusão entre tecnologias analógicas e numéricas (integração de redes) - e só se incrementa desde então. Essas redes não transmitem correntes elétricas, mas informação, isto é, poder. A informática é uma espécie de escritura e era ela que Derrida antevia na Gramatologia: história da evolução cibernética da linguagem ${ }^{2}$. Hoje a difusão da informação é dada pelas indústrias de programas, que comandam a própria possibilidade dos acontecimentos à medida que o "cobrem" em tempo real, que virou o próprio tempo enquanto ausência de tempo. Toda memória é seleção; só é possível lembrar esquecendo (STIEGLER, 1996, pp. 123-34). Assim, as indústrias de programas selecionam acontecimentos a partir da sua capacidade de provocar valor, produzindo o presente em "tempo real" e com isso evitando o trabalho da diferença (nesse caso, bem próxima da ideia de delay), que é o que viabiliza o pensamento reflexivo. $\mathrm{O}$ curto-circuito elimina a reflexividade, num pathos (sensacionalismo) que hoje é mundial (STIEGLER, 2008, pp. 97-155; 2004, pp. 15-60; 2006a, pp. 117-45).

Uma breve comparação pode ajudar a perceber a dimensão da proposta do filósofo francês. A recente obra A Sociedade Excitada, de Christoph Türcke, trabalha temas muito semelhantes e com enfoque em geral parecido com o de Bernard Stiegler. Türcke naturaliza ao extremo as ideias de espírito e inteligência a partir das conexões neurológicas dos indivíduos em conexão com a natureza e do conceito psicanalítico de compulsão à repetição, enquanto neutralização do choque da natureza mediante uma permanente elaboração repetitiva do evento (TÜRCKE, 2010a, pp. 140-1). Com isso, Türcke, na mesma linha de Stiegler, detecta como a imagem fomentada pela publicidade e pelo marketing - em uma versão radicalizada da ideia de sociedade do espetáculo de Debord (TÜRCKE, 2010a, p. 10) - capta a atenção dos consumidores e provoca gradualmente a destruição das conexões neurológicas traçadas mediante um longo trabalho humano até chegar ao pensamento. Em Türcke, contudo, é possível ainda ver uma herança da ideia de espírito clássica da filosofia, à medida que o "interior" é autorreferido, ainda que naturalizado e historicizado. Mediante rituais que começam pelo sacrifício humano até se chegar ao pensamento, o humano executa um trabalho interno que gradualmente se exterioriza até retornar a si mesmo em forma de pensamento. E é essa esfera do pensamento que a sociedade do espetáculo está destruindo mediante um curto-circuito cerebral em que a maquinaria contemporânea "atalha" o caminho, destruindo o trabalho neurológico necessário do espírito até chegar ao pensamento (TÜRCKE, 2010a, p. 292; 2010b, pp. 131212). Para dar conta do espírito, Türcke levanta a insuficiência tanto das explicações neurocientíficas quanto da ideia de auto-organização. Como se chega a essa unidade organizativa da consciência, para ele, é questão que não pode ser explicada - espécie de "milagre" (2010a, pp. 130-1).

Para Stiegler, ao contrário, o "espírito” precisa estar inscrito em algum suporte, de modo que a noção de emancipação não pode estar desvinculada de um certo processo técnico que dê conta dele enquanto suporte. Como o pharmakon, a tecnologia pode ser terapêutica ou venenosa, mas é impossível - como mostrara Derrida na Farmácia de Platão (DERRIDA, 1972 e 2005; PINTO NETO, 2013b) - constituir uma interioridade pura, um "estado-da-alma" desvinculado de uma escritura própria, ainda que esse espírito seja eminentemente social (quer dizer, intersubjetivo) (STIEGLER, 2010, p. 21; 2007, pp. 7887; FERREIRA e AMARAL, 2008). Assim, para Stiegler a crítica da economia política contemporânea amparada na sociedade de consumo e na proletarização generalizada da sensibilidade - deve estar atenta aos novos pharmaka que emergem, sem se deixar levar pelo preconceito com a técnica. A maquinaria é essencial ao humano, à medida que ele constitui o pensamento como escritura. As novas tecnologias da informação - por exemplo, a economia contributiva que surge a partir das tecnologias relacionais da Internet - são para Stiegler a possibilidade de desenvolvimento de novos suportes para a fecundação terapêutica de um novo espírito pós-capitalista, baseado no modelo colaborativo e capaz de se desvincular da estrutura que Marx apresentou (STIEGLER, 2010, pp. 66-70; 2004, 198-211; 2006b, pp. 57-62).

\section{NOTAS}

1. Afora textos publicados em seminários dedicados a Derrida, nos quais o autor desempenha papel secundário, somente uma obra até agora foi traduzida ao português: "Reflexões (não) contemporâneas", coletânea de textos organizada por Maria Beatriz de Medeiros e publicada pela editora Argos. Praticamente sozinhos, Diego Viana, Jonatas Ferreira e 
Aécio Amaral são pesquisadores que desenvolvem o pensamento de Stiegler no Brasil (ver VIANA, 2008; FERREIRA e AMARAL, 2008). Laymert Garcia dos Santos também aborda en passant o autor, embora com viés crítico (SANTOS, 2005). Urge a tradução, por exemplo, no mínimo, do primeiro volume de A técnica e o tempo, obra de alto impacto do mundo acadêmico, para o português.

2. Sobre a relação entre o pensamento de Derrida e a cibernética, conferir DERRIDA, 1962 e 2004; JOHNSON,1993 e 2001; KIRBY,2009 e 2010 e PINTO NETO, 2013a e 2013b.

\section{REFERÊNCIAS}

DERRIDA, J. 1962. Introduction. In: HUSSERL, E. L'Origine de la géométrie. Paris: PUF. 1967. De la Grammatologie. Paris: Les éditions de Minuit. . 1972. La Dissémination. Paris: Éditions du Seul. .2004. Gramatologia. São Paulo: Perspectiva. .2005. A Farmácia de Platão. São Paulo: Iluminuras. \& STIEGLER, B. 2002. Echographies of Television. Polity.

FERREIRA, J. \& AMARAL, A. 2008. Memória eletrônica e desterritorialização. In: Política e Sociedade, n. 4, pp. 137-66.

JOHNSON, C. 1993. System and writting in the philosophy of Jacques Derrida. Cambridge: Cambridge University Press.

2001. Derrida: a cena da escritura. São Paulo: Editora UNESP.

KIRBY, V. 2009. Tracing life: 'la vie la mort'. In: The new continental review, v. 9, n. 1, pp. 107-26. Michigan: Michigan State University Press.

.2010. Original science: nature deconstructing itself. In: Derrida Today, 3, 2. Edimburgo: Edinburgh University Press.

LEROI-GOURHAN, A. 1983a. O Gesto e a Palavra, vol. I - Técnica e Linguagem. Porto: Edições 70. . 1983b. O Gesto e a Palavra, vol. II - Memória e Ritmos. Porto: Edições 70.

PINTO NETO, M. 2013a. A escritura da natureza: Derrida e o materialismo experimental. Porto Alegre. (Tese de doutorado).

.2013b. Nós fora de nós: Derrida, Stiegler e os sistemas de cognição estendida. In: Sapere Aude, v. 4, n. 7, pp. 329-46. Belo Horizonte: PUC Minas.

SANTOS, L. G. dos. 2005. Demasiadamente pós-humano. In: Novos estudos CEBRAP, n. 72. São Paulo: CEBRAP.

SIMONDON, G. 1989. Du mode d'existence des objets techniques. Paris: Aubier.

STIEGLER, B. 1996. La Technique et le temps, 2 - La Désorientacion. Paris: Galilée. 1998. Technics and Time, 1: the fault of Epimetheus. Stanford: Stanford California. .2001. La Technique et le temps, 3 - Le temps du cinéma et la question du mal-être. Paris: Galilée.

.2002. Derrida and technology: fidelity at the limits of deconstruction and the prosthesis of faith. In: COHEN, T. (org.). Jacques Derrida and the humanities. Cambridge: Cambridge University Press. .2004. Mécreance et discrédit, 1 - La décadence des démocraties industrielles. Paris: Galilée. .2006a. Mécreance et discrédit, 2 - Les sociétés incontrôlables d'individus désaffectés. Paris: Galilée. .2006b. Mécréance et discrédit, 3 - L'esprit perdu du capitalisme. Paris: Galilée. .2007. Reflexões (não) contemporâneas. Chapecó: Argos. 
2008. La télécratie contre la démocratie: lettre ouverte aux représentants politiques. Paris: Flammarion.

.2009. Magic Skin: or, the Franco-european accident of philosophy after Jacques Derrida. In: Qui Parle, v. 18, n. 1. Nebraska: University Nebraska Press.

.2010. For a new critique of political economy. London: Polity.

TÜRCKE, C. 2010a. Sociedade Excitada: filosofia da sensação. Campinas: Editora da UNICAMP. .2010b. Filosofia do Sonho. Ijuí: Uniijuí.

VIANA, D. 2008. Entrevista com Bernard Stiegler. In: Breviário de Filosofia Pública, n. 21, Agosto. Rio de Janeiro: UFF. 